\title{
A General Comparison Between Artemisia Herba Alba and Artemisia Tridentata
}

\author{
Ahmed Salem \\ Biology Department, The Northern Borders University, Saudi Arabia \\ ahmad-ani-27@hotmail.com
}

Abstract: This study aims to describe general differences between two species that descended from Artemisia. These comparisons will be discerptions of the differences in photosynthesis pathways, taxonomy, habitats, morphology,and growth form.

Keywords: Artemisia Herba Alba, Artemisia Tridentata, Photosynthesis Pathway, Adaptations, Drought Stress.

\section{INTRODUCTION}

Artemisia is a genus name in the generic nomenclature of plants for both Artemisia herba alba and Artemisia Tridentata that are only differentiate able at the final stage of the scientific rank of organisms called species. The species rank gives the two plants their second name Herba-Alba and Tridentata respectively (1). Exploring the Artemisia herba alba, it is commonly known as white wormwood, and it is a perennial shrub growing in the dry Mediterranean regions of North Africa or Sahara Maghreb. Artemisia herba alba is also found in some parts of Arabian Peninsula such as Western Asia and Europe (2). Again, Artemisia herba alba is an effective antispasmodic and antiseptic that finds several applications in the field of herbal medicine. Finally, Artemisia herba alba has a specific epithet in Latin meaning white herb for "Herba-Alba" as its leaves and stems are woolly and white (7)(19).

On the other side, Artemisia Tridentata has several alternative names such as sagebrush, Big sagebrush, or Great Basin sagebrush. Artemisia Tridentata is an aromatic shrub that grows in arid conditions such as cold deserts, mountains, and steppe habitats with its common region being North America. It is important to note that the common name sagebrush refers to several members of genus Artemisia and Artemisia shrubs are the common plant species in the Great Basin (8). However, the Artemisia species have several threats, such as conversion of land for agricultural use, human settlement, invasive plant species, livestock grazing, climate changes, and wildfires (7).

\section{TAXONOMY}

Taxonomy involves scientific classification of organisms using the rank that includes various classes of specificity such as kingdom, subkingdom, super-division, division, class, subclass, order, family, genus, and species. A kingdom is the broad category, while species are the simplest and specific category. All living organisms get their two scientific names from genus and species respectively. Both Artemisia herba alba and Artemisia Tridentata are close relatives and consequently share a great deal in the scientific naming system as they are similar from the top broad category, kingdom up to genus category. The two plants are only distinguishable at the final category of the scientific rank, species.3

Artemisia herba alba and Artemisia Tridentata belong to Kingdom Plantae that include all plants, Subkingdom Tracheobionta for vascular plants, and super-division Spermatophyta that includes seed plants. The division rank of both Artemisia herba alba and Artemisia Tridentata is Magnoliophyta that includes flowering plants, class for the two plants is Magnoliopsida that includes dicotyledonous plants, and subclass for the two is Asteridae. Again, both Artemisia herba alba and Artemisia Tridentata share the order in the scientific rank 
called asterales, and their family rank is Asteraceae or Compositae for Aster family.4 The genus rank for the two plants is Astemisia. However, Artemisia herba alba belongs to the species rank of Herba-Alba that gives it its second name, while Artemisia Tridentata belong to species rank Tridentata that also defines its second name.

\section{HABITAT}

Artemisia herba alba and Artemisia Tridentata commonly dominate arid and semi-arid regions. However, Artemisia herba alba and Artemisia Tridentata are not desert plants, but rather residents of steppe in regions that receives about 18 to 40 centimeters of annual precipitation. Again, Artemisia herba alba and Artemisia Tridentata dominate the Great Basin areas covering about one million kilometer square in the eleven States of America and Canadian provinces (8).

\section{MORPHOLOGY}

Artemisia herba alba grows in a range of 20 to 40 centimeters tall. It has strongly aromatic leaves that are covered with fine granular hair (10). The fine granular hair reflects the sunlight rays that give the grayish aspect of the Artemisia herba alba (10). Again, the leaves of Artemisia herba alba shoots are gray in color, ovate to orbicular, petiolate in its outline. On the other side, the leaves of Artemisia herba alba flowering stems are smaller and abundant in the winter. The flowering heads of Artemisia herba alba are sessile, tapering, and oblong at their bases. The Artemisia herba alba are known to flower in periods within September to December. Finally, the receptacle of the Artemisia herba alba is marked with two to five yellowish hermaphrodite flowers in every head (11).

On the other hand, Artemisia Tridentata is a pale-gray shrub with many branches. The branches bear silverygray foliage and yellow flowers that are about 0.5 to 3 meters tall. Again, Artemisia Tridentata plants have deep taproots of about one to four centimeters in length that are coupled with other lateral spreading roots near the earth's surface. The lateral roots near the surface enable the Artemisia Tridentata plant to absorb water from the surface while the taproots absorb water several meters down the soil. It is important to note that tall Artemisia Tridentata over one meter is usual indicators of arable land due to its preference for deep and basic soils. Again, Artemisia Tridentata plants are long-lived once they grow past their seedling stage and can stay for over one hundred years alive (12).

In terms of water relations, every species has its own way to survive under stress.6 Artemisia Tridentata closes stomata before leaf water potential reaches -30 bars. 6 However, Artemisia herba alba still opnes them when leaf water potential reaches -163 bars. 5

In comparison, both Artemisia herba alba and Artemisia Tridentata have strong pungent fragrance, especially when wet because they have terpenoids, camphor, and other volatile organic oils. The two plants also have bitter tastes and bad odor that play the role of protection by keeping herbivores away from feeding on them (13). Again, Artemisia herba alba and Artemisia Tridentata are evergreen plants that keep some of their leaves all year-round (13). However, both of the plants lose their leaves in the late summer. Artemisia herba alba and Artemisia Tridentata have wedge-shaped axillary nodes with branches that attach their leaves. Their leaves are approximately one to three centimeter long and up to one centimeter broad. It is important to note that Artemisia Tridentata leaves have wider outer tips that are divided into three lobes that define its second name Tridentata. The leaves of both Artemisia herba alba and Artemisia Tridentata are covered with silvery hairs that are very fine.

Again, both Artemisia herba alba and Artemisia Tridentata are known to flower in the early fall or late summer. Their flowers are yellow in color, small, and are in long and loosely arranged tubular clusters. The two plants bear seed-like fruits with small amount of hairs on their surfaces. Artemisia herba alba and Artemisia Tridentata can also reproduce via sprouts that shoot up from their underground rhizomes. It is important to note that the 
sprouts are extensions of the parental plants while the seedlings are independent individuals to any other plant. Among the two methods of reproduction of both Artemisia herba alba and Artemisia Tridentata, seedlings require favorable environment regarding moisture and warmth to germinate and survival, especially at their early stages of growth (16). On the other side, sprouts are connected to stable and healthy parent plants that provide necessary materials for their survival (14).

\section{PHOTOSYNTHETIC PATHWAYS}

Artemisia herba alba and Artemisia Tridentata are known to follow C3 and CAM photosynthetic pathways because the process requires little water and saves the water in the semi-arid and arid habitats. The process of photosynthesis has three distinct processes C3, C4, and CAM with every type having both advantages and disadvantages for plants in various habitats (20). However, all the three types of photosynthesis rely on two biochemical pathways of light reaction and dark stage. The light reaction involves chlorophyll absorbing light energy that is transferred to hydrogen ions split from water molecules (14). The splitting of water molecules leads to the release of oxygen gas. On the other side, the dark stage, also known as carbon fixation takes carbon dioxide from the air and makes sugars using the energy from the light reaction stage (13). The end-result is formation of sugar molecules with stored energy in the carbon-carbon bonds in the sugar molecule structures (11).

However, the three processes of photosynthesis vary in their pathways. Plants in habitats with sufficient water carry out "normal" or C3 photosynthesis that involves RuBP carboxylase enzyme that takes up carbon dioxide. The process of RuBP carboxylase enzyme reaction is fine in the presence of more carbon dioxide that oxygen (15). However, in the presence of more oxygen that carbon dioxide, photorespiration takes place where the enzyme takes up oxygen instead of the normal carbon dioxide. It is important to note that photorespiration does not lead to production of sugars. Normally, the produced oxygen exits the plant's leaves through the stomata, but on condition of inadequate water, oxygen concentration can build up an initiate photorespiration (17).

The second type of photosynthesis is called C4 that has two unique ways. First, it uses PEP carboxylase enzyme to take up carbon dioxide instead of RuBP carboxylase enzymes. In C4 photosynthesis, photorespiration cannot occur because enzyme PEP carboxylase cannot bind to oxygen. The mechanism of PEP carboxylase is advantageous to plants in dry and hot conditions that require the stomata to be closed to prevent excess dehydration of the plant. Secondly, the C4 photosynthesis involves different cells for various reaction processes contrary to the "normal" photosynthesis. Enzyme PEP carboxylase takes up carbon in the mesophyll cells and adds it to another three carbon chemicals that define the name C4 photosynthesis. The three carbon chemicals are known as oxaloacetate (17).

The third form of photosynthesis is known as Crassulacean-Acid Metabolism or CAM photosynthesis that is common in plants in desert habitats. CAM photosynthesis involves taking carbon dioxide only at night, then stored in the leave vacuoles. The storage of carbon dioxide in the leave vacuoles leads to the buildup of acidic oxaloacetate (9). Meaning the stomata are only open at night, because the conditions are cool and humid, and closed during the day when the conditions are dry and hot to reduce excess dehydration of the plants. In the sunrise, the light from the sun initiate the light reaction stage of photosynthesis to take place, and the stored carbon combines with sugars (16). However, the stored carbon depletes quickly, and the process ceases. Consequently, a little sugar is produced, and the plant can manage the dry conditions at the expense of their rapid growth (18). The phenomenon explains the slow rate of growth in most desert plants and the heavy investment of their energy into defensive structures such as spines and chemicals because they cannot tolerate losing their hard-earned biomass. In conclusion, the C3 photosynthesis is common in plants in moist habitats while C4 and CAM photosynthesis are common in plants in dry conditions such as Artemisia herba alba and Artemisia Tridentata (21). 


\section{ADAPTATIONS TO DROUGHT STRESS}

Artemisia herba alba and Artemisia Tridentata have several features and adaptations that enable them to survive the tough conditions of semi-arid and arid areas that are their preferred habitat. First, Artemisia herba alba and Artemisia Tridentata have an extensive taproot system that enables them to absorb water deep underground. Again, they have lateral roots that are shallow for quick response to light rainfall (22). Secondly, the stems of Artemisia herba alba and Artemisia Tridentata are waxy and wooly. The waxy is impermeable to evaporating water from the plant while the wooly structures of the stem allow space for maximum water storage (Omics). Thirdly, the leaves of both Artemisia herba alba and Artemisia Tridentata have reduced surface areas that minimize that chance of water evaporation from the surfaces of the leaves (18).

In conclusion, Artemisia herba alba and Artemisia Tridentata grow to a height of 20 to 40 centimeters tall. They have strongly aromatic leaves that are covered with fine granular hair that reflect the sunlight rays that give them the grayish aspect. Again, their leave shoots are gray in color, ovate to orbicular, petiolate in its outline. The two plants are known to flower in periods within September to December. Both Artemisia herba alba and Artemisia Tridentata have branches that bear silvery-gray foliage and yellow flowers that are about 0.5 to 3 meters tall. Again, they have deep taproots of about one to four centimeters in length that are coupled with other lateral spreading roots near the earth's surface to respond to drought stress that is common in their preferred habitats. The lateral roots near the surface enable them to absorb water from the surface while the taproots absorb water several meters down the soil. Tall Artemisia herba alba and Artemisia Tridentata over one meter are usually indicators of arable land due to their preference for deep and basic soils. Artemisia herba alba and Artemisia Tridentata plants are long-lived once they grow past their seedling stage and can stay for over one hundred years alive.

\section{WORKS CITED}

“Classification | USDA PLANTS." Classification | USDA PLANTS. N.p., n.d. Web. 05 Nov. 2016.

1. "The Taxonomy of "Wormwoods" and Related Artemisia Species." The Taxonomy of "Wormwoods" and Related Artemisia Species. N.p., n.d. Web. 16 Nov. 2016.

2. Mansour Jahantigh and Mohammad Pessarakli "Forage production response of Artemisia herba alba to variation in rainfall and changes in soil conditions in arid regions." Journal of Food, Agriculture \& Environment Vol.7 (3\&4) : 717-722. 2009.

3. McArthur, E. Durant; Freeman, D. Carl; Graham, John H.; [and others]. 1998. Narrow hybrid zone between two subspecies of big sagebrush (Artemisia tridentata: Asteraceae). VI. Respiration and water potential. Canadian Journal of Botany. 76(4): 567-574. [29357]

4. Meyer, Susan E.; Kitchen, Stanley; Wilson, G. Richard; Stevens, Richard. 1988. Proposal: Addition of Artemisia tridentata--big sagebrush to the rules. Newsletter of the Association of Official Seed Analysts. 62(1): 17-18. [5521]

5. Kappen, L., O. L. Lange, E. -D. Schulze, M. Evenari, and U. Buschbom. "ExtremeWater Stress and Photosynthetic Activity of the Desert Plant Artemisia herba alba Asso." Oecologia 10.2 (1972): 177-82. Web

6. Romo, J. T., and M. R. Haferkamp. "Water Relations of Artemisia Tridentata Ssp. Wyomingensis and Sarcobatus Vermiculatus in the Steppe of Southeastern Oregon." American Midland Naturalist 121.1 (1989): 155. Web.

7. Lakehal, Samah and Meliani A. "Essential Oil Composition and Antimicrobial Activity of Artemisia Herba- Alba Asso Grown In Algeria”. Med chem (Los Angeles) 6.6 (2016): n. pag. Web.

8. Ibrahim, K., S. Abd-Alla, and S. El-Toukhy. "Potentiaity Of Native Range Plants Under Different Habitats From Elarish To El-Kantara District (North Eastern Coast Of Egypt)”. met 18.1 (2007): 21-37. Web. 
9. Abderrahman, Salim M. and Seba Jamal Shbailat. "Genotoxic And Cytotoxic Effects Of Artemisia herba alba On Mammalian Cells". Caryologia 67.4 (2014): 265-272. Web.

10. Martirosyan, Varsik, and Yosef Steinberger. "Microbial Functional Diversity in the Phyllosphere and Laimosphere of Different Desert Plants." Journal of Arid Environments 107 (2014): 26-33. Web.

11. Aziz, Mohammed. "Relaxant Effect Of Essential Oil Of Artemisia herba alba Asso. On Rodent Jejunum Contractions". Scientia Pharmaceutica 80.2 (2012): 457-467. Web.

12. Stephen B. and Nancy L. "Big Sagebrush (Artemisia Tridentata) Communities - Ecology, Importance and Restoration Potential." Van Nostrand's Scientific Encyclopedia(2005): n. pag. Web.

13. Sullivan, T.P., D.S. Sullivan, and H.M.A. Thistlewood. "Abundance And Diversity Of Small Mammals In Response To Various Linear Habitats In Semi-Arid Agricultural Landscapes". Journal of Arid Environments 83 (2012): 54-61. Web.

14. Lindsey, P.A. and J.D. Skinner. "Ant Composition and Activity Patterns As Determined By Pitfall Trapping and Other Methods In Three Habitats In The Semi-Arid Karoo". Journal of Arid Environments 48.4 (2001): 551-568. Web.

15. Mohamed, Abou, Abeer Esmail, and Adila El-Saade. “Terpenes From Artemisia Herba-Alba”. ResearchGate. N.p., 2013. Web. 5 Sept. 2016.

16. Alhamad, M.N. et al. "Relationships Between Herbaceous Diversity And Biomass In Two Habitats In Arid Mediterranean Rangeland". Journal of Arid Environments 74.2 (2010): 277-283. Web.

17. Mohsen, Haouari and Ferchichi Ali. "Essential Oil Composition Of Artemisia herba alba From Southern Tunisia". Molecules 14.4 (2009): 1585-1594. Web.

18. Kadono, Yasuro. "Morphology And Ecology Of Podostemaceae-A Brief Review". Plant Morphol 4.1 (1992): 18-22. Web.

19. Mohamed, Abou El-Hamd H., Abeer M. Esmail, and Adila M. El-Saade. "Terpenes From Artemisia Herba-Alba". Zeitschrift für Naturforschung C 68.9-10 (2013): n. pag. Web.

20. Noor, Mehwish Jamil et al. "RETRACTED ARTICLE: Floristic And Ethnoecological Diversity In Various Habitats Of A Semi-Arid Area In The Chakwal District (Pakistan), With Special Emphasis On Medicinal Plants". Plant Ecol 217.7 (2014): 943-943. Web.

21. Nishida, Harufumi. "Contributions Of Permineralized Plant Fossils To Plant Morphology". Plant Morphol 16.1 (2004): 93-102. Web.

22. Homrani-Bakali, Abdelmonaim. "Effect Of Various Pre-Treatments And Alternating Temperature On Seed Germination Of Artemisia herba alba Asso". JPS 4.1 (2014): n. pag. Web.

23. Absinthe, Education. "The Taxonomy Of "Wormwoods” And Related Artemisia Species”. Wormwoodsociety. org. N.p., 2016. Web. 5 Sept. 2016.

Citation: Ahmed Salem, Biology Department, The Northern Borders University, Saudi Arabia, "A General Comparison Between Artemisia Herba Alba and Artemisia Tridentata". American Research Journal of Biosciences Volume 2016; pp:1-5

Copyright (c) 2016 Ahmed Salem, This is an open access article distributed under the Creative Commons Attribution License, which permits unrestricted use, distribution, and reproduction in any medium, provided the original work is properly cited. 